\title{
Sucrose aversions in mice as a result of injected nicotine or passive tobacco smoke inhalation
}

\author{
FRANK ETSCORN \\ New Mexico Institute of Mining and Technology, Socorro, New Mexico 87801
}

\begin{abstract}
Two studies using Swiss-Webster mice demonstrated that a delayed nicotine injection or passive tobacco smoking are effective treatments for conditioning sucrose aversions. The results are discussed in relation to future research as well as possible implications for human health.
\end{abstract}

Conditioned food aversions have been established using a wide variety of chemical agents (Riley \& Clarke, 1977); however, the route of administration has typically been intraperitoneal injection or gastric intubation. Interestingly, only three studies have explored food aversion learning using inhaled conditioning agents. Hunt and Kimeldorf (1967) allowed rats to drink an aqueous solution of saccharin; this was followed by deep surgical anesthesia with ethyl ether during exposure to whole-body irradiation. For the present purposes, comment will be limited to a control group that drank saccharin solution before undergoing ether anesthesia without X-irradiation. Simply put, there was no measured aversion to the saccharin.

Berger (1972) used ether anesthesia in an attempt to condition aversions to an aqueous solution of sweetened condensed milk. Specifically, drinking latencies to consume the milk were measured following immersion in an ether jar until anesthesia without reference to dosimetry. During posttests the rats previously anesthetized with ether displayed drinking latencies equivalent to saline-injected controls. These findings are intriguing in that humans frequently exhibit postanesthesia nausea and emesis following the use of ether (Goodman \& Gillman, 1975).

Finally, Goudie and Dickens (1978) showed that for rats an $80 \%$ (but not a $60 \%$ ) concentration of nitrous oxide in $\mathrm{O}_{2}$ was capable of inducing an aversion to a $.1 \%$ aqueous saccharin solution after four conditioning trials using one-bottle tests. A second study using the more sensitive two-bottle choice test demonstrated that the strength of nitrous oxide-induced aversions varies as a function of drug duration. In each of the studies, however, as the authors note, the aversions were not pronounced.

The present study asks the following questions: (1) Is the powerful emetic (Laffan \& Borison, 1957) and convulsant (Domino, 1967), nicotine, which has a

This work was supported by a New Mexico Tech Faculty Research Grant. relatively short (.92- to 1.10 -h) biological half-life in rats (Miller, Rotenberg, \& Adir, 1977), capable of conditioning sucrose aversions in mice at subconvulsant doses? (2) Is passive tobacco smoke inhalation an effective treatment for conditioning sucrose aversions?

\section{EXPERIMENT 1}

Of the numerous drugs demonstrated to be effective for conditioning food aversions, no attempts have been reported in which nicotine was used as the corditioning agent. This study was therefore undertaken in order to determine if injected nicotine produces sucrose aversions in mice.

\section{Method}

Animals. Twelve 30-day-old male Swiss-Webster mice were selected as subjects. Each mouse was housed in an individual plastic cage $(18.5 \times 29.2 \times 12.7 \mathrm{~cm}$ high $)$ fitted with a wire-bar lid. Purina Mouse Chow was available for the duration of the study. Covering the floor of each cage was approximately $2 \mathrm{~cm}$ of aspen shavings. Laboratory temperature was thermostatically controlled $\left(25^{\circ} \mathrm{C} \pm 1^{\circ} \mathrm{C}\right)$, and overhead fluorescent strips were cycled on at 7:00 a.m. and off at 7:00 p.m. The mice remained in their home cages at all times except for weighing, injecting, and cage cleaning.

Apparatus. For all animals, test solutions were offered from calibrated $(.2-\mathrm{ml})$ drinking tubes fashioned from disposable plastic syringes. The drinking tubes were fitted with $5-\mathrm{cm}$ stainless steel sipper tubes. Each cage lid was designed to accommodate two drinking tubes with the spout tips protruding approximately $5 \mathrm{~cm}$ into the central portion of the cage. The spout tips were approximately $2 \mathrm{~cm}$ apart.

Procedure. All animals had free access to fresh tap water for 2 weeks prior to the beginning of the experiment. On Day 1 at approximately 10:00 a.m., all mice were deprived of freely available tap water until the same time on the following day (Day 2), when each animal was allowed 15 min access to tap water from one of two available drinking tubes. Both tubes were simultaneously inserted into each cage using a 5-sec/cage schedule. The cage position of the full tube (either on the right or the left relative to the experimenter) across all animals was determined according to a counterbalanced sequence (RLLRRL). Following the allotted $15 \mathrm{~min}$ of drinking, the tubes were removed (using the 5-sec schedule), and the amounts consumed were determined and recorded for each mouse. This daily drinking regimen was continued until a total of six measures were taken (Days 2-7). 
Table 1

Summary of Procedures and Results: Nicotine Aversion

\begin{tabular}{lrrrr}
\hline & \multicolumn{5}{c}{ Mean Sucrose Preference } \\
\cline { 2 - 5 } \multicolumn{1}{c}{ Group } & 1 & 2 & 3 & 4 \\
\hline 1. Sweet Water/Nicotine Injection & 8 & 14 & 27 & 50 \\
2. Sweet Water/Saline Injection & 67 & 88 & 96 & 97 \\
3. Plain Water/Nicotine Injection & 71 & 71 & 84 & 90 \\
\hline
\end{tabular}

On Day 8 (conditioning day), the animals were randomly assigned to three equal groups, weighed, and returned to their home cages. Approximately $1 \mathrm{~h}$ later (10:00 a.m.), each animal in Groups 1 and 2 received $15 \mathrm{~min}$ access to two tubes filled with a freshly prepared sucrose solution $(20 \% \mathrm{w} / \mathrm{v})$. Group 3 animals each had two tubes of unflavored tap water available for $15 \mathrm{~min}$. Following $15 \mathrm{~min}$ access, the tubes were removed, and the amounts consumed were determined and recorded for each animal. After a 15-min delay, Group 1 received the conditioning agent, nicotine, at a dosage of $2 \mathrm{mg} / \mathrm{kg}$ (from a solution of $.33 \mathrm{mg}$ nicotine per milliliter of $.9 \%$ saline solution). Group 2 was treated identically except that an equivolume injection of $.9 \%$ saline solution was substituted for nicotine. Group 3 animals were injected with a $2-\mathrm{mg} / \mathrm{kg}$ dose of nicotine. All injections were given intraperitoneally with 25 -guage needles. The three groups and their respective treatments are depicted in Table 1.

On Days 9 and 10, the animals were returned to baseline drinking using two tubes: one filled with plain tap water, the other empty. The tube positions were switched for each animal on Day 10.

Days 11-14 were test days, on which all subjects were simultaneously given the choice of drinking for $15 \mathrm{~min}$ from a tube containing sucrose solution or from one containing unflavored water. For Test Day 1 the sucrose solution was on the right side of the cage for all animals; thereafter, sucrose placement adhered to a RLLR counterbalance.

\section{Results}

Prior to statistical analysis, sucrose preference scores were computed for each subject on each test day using the following formula: amount of sucrose solution consumed divided by the total of both fluids consumed multipled by 100 . Table 1 shows the mean sucrose preference score for each treatment group on Test Days 1-4.

Consumption data (sucrose indexes) for Test Days 1-4 were analyzed using a two-factor (conditions by trials) analysis of variance (ANOVA) with repeated measures on trials. The main effects of conditions $[\mathrm{F}(2,36)=46.03, \mathrm{p}<.001]$ and trials $[\mathrm{F}(3,36)=5.26$, $\mathrm{p}<.05]$ were significant. There was no interaction $(\mathrm{F}<1)$. A Duncan's multiple-range test was used to determine that the sweet water/nicotine-injected group demonstrated a significant reduction in sucrose preference on Test Day 1 compared with the preferences exhibited by the two control groups $(p<.01)$. The experimental group likewise differed from the two control groups on Test Days $2-4(p<.01$ in each case; Duncan's multiple-range test).

On the last baseline drinking day (Day 7) ANOVA was used to determine that the three groups were drinking equivalent amounts of plain water prior to experimental treatment $[F(2,9)=.51]$.
On conditioning day, ANOVA was used to compare weights across the three groups of subjects; no differences were observed $[F(2,9)=.94]$. Weights for all subjects averaged $18.9 \mathrm{~g}(\mathrm{SD}=1.03)$. Although the animals allowed sweet water on conditioning day drank slightly more than plain-water animals (mean $=2.6 \mathrm{ml}$ vs. $2.4 \mathrm{ml}$ ), the difference did not reach statistical significance $[F(1,10)=1.15]$.

Recovery day drinking was analyzed (separate oneway ANOVAs) across the three groups for Recovery Days 1 and 2, with no differences found ( $F<1$ in each case).

\section{EXPERIMENT 2}

Experiment 2 was designed to assess the effectiveness of passive tobacco smoking for conditioning food aversion.

\section{Method}

Animals. Fifteen 30-day-old Swiss-Webster mice maintained identically as the mice in Experiment 1 were used as subjects. Separate rooms having independent air sources were used for exposing groups of mice to either tobacco smoke or sham conditions.

Apparatus. For tobacco smoke exposure as well as sham (ambient air) exposure, respective groups of mice were confined in a clear plastic tank $(26.5 \times 37 \times 16.5 \mathrm{~cm}$ high $)$. The tank was designed to accommodate five mice, with each mouse separated from the others by hardware cloth partitions $(6-\mathrm{mm}$ mesh, galvanized). A tight-fitting plastic top with five $6-\mathrm{mm}$ holes centered over each compartment covered the exposure tank. Individual gas inlets were provided for each compartment; each inlet was designed to accept $1-\mathrm{cm}$ outside-diameter plastic aquarium tubing. Ambient air or tobacco smoke was pumped into the tank by using a $30-\mathrm{ml}$ plastic disposable syringe. A three-way Teflon valve was used to route smoke from the lit cigarette to the $30-\mathrm{ml}$ syringe and from the syringe to a five-way metal aquarium valve that was used for routing the smoke to each compartment's smoke inlet. Plastic aquarium tubing was used for all interconnections. Five gas inputs (one for each animal compartment) were selected over one gas input for the entire exposure tank for purposes of more even smoke distribution.

Tobacco smoke was generated from fresh nonfilter regularlength cigarettes (the particular brand averaging $23 \mathrm{mg}$ of tar and $1.4 \mathrm{mg}$ of nicotine per cigarette).

Procedure. The mice were baselined as in Experiment 1 until a total of 10 measures were taken (Days 2-11).

On Day 12 (conditioning day), the animals were randomily assigned to three equal groups. Group 1 received $15 \mathrm{~min}$ access to a sucrose solution (freshly prepared using tap water, $20 \% \mathrm{w} / \mathrm{v}$ ) from two available tubes, after which a 30-min interval was allowed to elapse. At the end of the 30 -min interval, the animals were placed in the exposure device, and $1 \mathrm{~min}$ later they were introduced to the smoke. Smoke exposure proceeded as follows: A fresh cigarette was placed in the holder and lit with a match by taking two 30-ml "puffs" with the syringe (the two lighting puffs were not pumped into the exposure device). Following the lighting procedure, a total of $210 \mathrm{ml}$ of smoke (seven cycles of the $30-\mathrm{ml}$ syringe) was pumped into the exposure device in a 1 -min interval. The subjects remained in the exposure device for an additional $3 \mathrm{~min}$ (total exposure of $4 \mathrm{~min}$ ), after which the top was removed and the animals were returned to their home cages. After conditioning treatment for Group 1, Group 2 (sham exposure) received the same treatment, except that the cigarette 
Table 2

Summary of Procedures and Results (Mean Sucrose Preference on Test Day): Smoke Aversion

\begin{tabular}{lc}
\hline Group & Result \\
\hline 1. Sweet Water/Tobacco Smoke & 27 \\
2. Sweet Water/Sham (Cigarette Unlit) & 69 \\
3. Plain Water/Tobacco Smoke & 60 \\
\hline
\end{tabular}

was never lit. Group 3 followed and was treated identically as Group 1, except that plain water was substituted for sweet water. Each group therefore received its entire experimental treatment before the next group was treated. The exposure device was washed with soap and water and dried before the next group was treated. The various groups and their respective treatments are depicted in Table 2.

On Days 13 and 14 the subjects were returned to baseline drinking, as in Experiment 1.

Day 15 consisted of sucrose solution and tap water choice tests for all mice, as in Experiment 1; however, cage placement of the sweet water and plain water drinking tubes was randomly determined for each mouse.

\section{Results}

The test day sucrose preference scores for all animals were analyzed using a one-way ANOVA. The computed ANOVA resulted in a significant overall difference $[F(2,12)=8.07, p<.01]$, and a Duncan's multiplerange test indicated that the sweet water/tobacco smoke group was reliably different from the two control groups $(\mathrm{p}<.01)$.

Water consumption was equivalent for the three groups on the last baseline day $[\mathrm{F}(2,12)=1.01$, n.s.] indicating similar consumption prior to experimental treatment. Likewise, there was no difference in water consumption between groups on the 2 recovery days $[F(2,12)=1.25$, n.s., and $F(2,12)=2.54$, n.s., respectively]. Liquid consumption was also analyzed on conditioning day, with no reliable difference observed $(\mathrm{F}<1)$. Finally, subject weights, as determined on the last baseline drinking session, were found not to differ $(\mathrm{F}<1)$.

\section{GENERAL DISCUSSION}

That nicotine produces conditioned food aversion is not surprising considering the direct stimulatory action of nicotine on the emetic chemoreceptor triggering zone in the area postrema of the medulla (Laffan \& Borison, 1957). Moreover, virtually all drugs studied thus far have produced some degree of aversion. It is, however, important that passive tobacco smoking is an effective treatment for aversion learning, albeit in the present studies, the injected nicotine appears to have produced a more powerful aversion than smoke inhalation. Obviously, dosimetry needs to be investigated parametrically. Although no attempt was made to partial out the actual agent(s) responsible for the conditioning, nicotine or carbon monoxide would be likely candidates. Dosimetry (ideally using gas chromatography) was not determined in Experiment 2, but more than likely, rather high doses of nicotine and/or carbon monoxide were involved.

The finding that mice acquire aversions due to passive smoking could have important implications for future work in this area. For example, it is well documented that human infants often exhibit various feeding-related problems such as finicalness, odd preferences, or food rejections. To speculate: Could food aversions acquired during infancy as a result of passive tobacco smoking partially account for the rejection of specific foods by children? In summary, we feel that an important extension of these studies would be to determine (1) the lowest dose of tobacco smoke effective for rodent aversion learning and (2) smoke concentrations encountered by human infants.

\section{REFERENCES}

BERgER, B. D. Conditioning of food aversions by injections of psychoactive drugs. Journal of Comparative and Physiological Psychology, 1972, 81, 21-26.

Domino, E. F. Electroencephalographical and behavioral arousal effects of small doses of nicotine: A neuropsychopharmacological study. Annals of the New York Academy of Science, 1967, 142.

Goodman, L. S., \& Gilman, A. (Eds.). The pharmacological basis of therapeutics (5th ed.). New York: Macmillan, 1975.

Goudie, A. J., \& Dickins, D. W. Nitrous oxide-induced conditioned taste aversions in rats: The role of duration of drug exposure and its relation to the taste aversion-self-administration "paradox." Pharmacology, Biochemistry and Behavior, 1978, 9, 587-592.

Hunt, E. L., \& Kimeldorf, D. J. The humoral factor in radiationinduced motivation. Radiation Research, 1967, 30, 404-419.

LAFFAn, R. J., \& Borison, H. L. Emetic action of nicotine and lobeline. Journal of Pharmacology and Experimental Therapy, 1957, 121, 468-476.

Mille R, R. P., Rotenberg, K. S., \& Adir, J. Effect of dose on the pharmacokinetics of intravenous nicotine in the rat. Drug Metabolism and Disposition, 1977, 5, 436-443.

RILEY, A. L., \& Clarke, C. M. Conditioned taste aversions: A bibliography. In L. M. Barker, M. R. Best, \& M. Domjan (Eds.), Learning mechanisms in food selection. Waco, Tex: Baylor University Press, 1967.

(Received for publication October 22, 1979.) 